\title{
A WELCOME TO THE SOCIETY
}

\author{
From John E。 Rinnet \\ President, The International Association for \\ Earthquake Engineering.
}

The formation of the New Zealand Society for Earthquake Engineering, as a Technical Group of the New Zealand Institution of Engineers, is of great import to earthquake engineers throughout the world. The International Association (IAEE) extends its congratulations. Everyone is deeply appreciative of the work of the New Zealand engineers and scientists in "the advancement of the science of earthquake engineering."

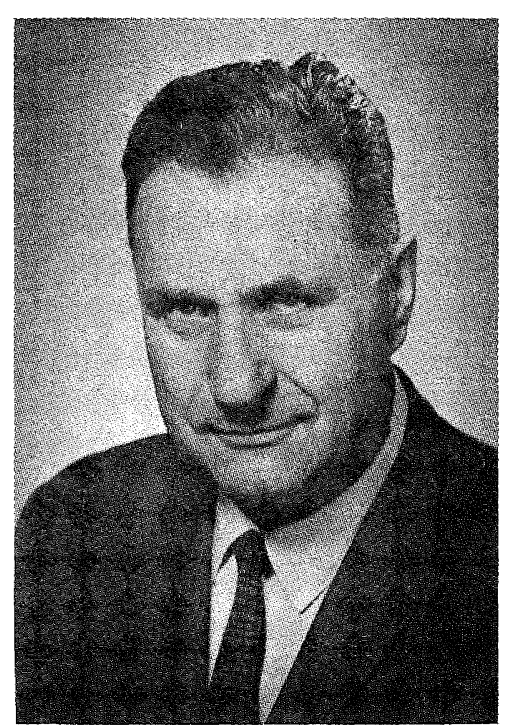

The quote is taken directly from the "Rules" and defines very cryptically the object of the Society. "Science" must be intended in a very broad sense. In a paper presented at 3 WCEE, a distinction was made by the writer between the science (in a stricter sense) and the art of earthquake engineering. Science was defined as the supporting earth sciences and the mathematical analyses of responses of structures to past earthquakes. Art was defined as applying the knowledge of science and mathematics to the design of structures and other facilities to be earthquakeresistant to unknown future earthquakes.

Much progress has been made in advancing the science in this more restricted sense. Not that we do not still have a long way to go in this field, but the urgent need now is the improvement of the art component of that dynarnic vector we call "earthquake engineering."

The design criteria most universally used in the practice of the art are codified into several well-recognised building codes. These are well-intended instruments for design, prepared by very capable earthquake engineers who have given generously of their time and efforts to provide criteria useful to the profession. The criteria are admittedly a vast oversimplification of what actually happens to a structure in a major

+ John E. Rinne, President I.A.E.E., Civil \& Structural Engineer with the Standard Oil Coy. of California; Vice President of the American Society of Civil Engineers. Elected Vice President I.A.E.E. after its formation in 1960. He succeeded Dr. Muto as President during the 3rd World Conference in Christchurch in 1965. 
earthquake. Too often they are applied "cook-book" fashion. And if the resulting "cake" falls flat (in inadequate performance), we are too ready to place the blame on the "recipe" and not the "cook". Criteria of this simplified type must be applied with much more understanding and application of the art of earthquake engineering, if practical and economical earthquake-resistant structures are to be achieved.

We have the capability to apply rather complex analyses to the design of structures. But, except in rare and unusual cases, practical results must be attainable within the total engineering effort that the usual structure can support and reimburse. For this reason, primarily, great reliance must be placed on the simplified codes. Therefore, any work we can do to improve these codes, without making them so complex as to be unwieldy, will be more effective in creating the desired earthquake resistance in our future designs than will be the now oft-repeated analyses of structural response to past or assumed ground motions. This is not to discourage the latter; it is only to try to emphasize the major needs.

of course, whatever we accumplish in either the science or the art of earthquake engineering, its good cannot be felt unless the new-found knowledge is applied. And it can not be applied if it is not known. Hence, the importance of disseminating our knowledge can not be over-emphasized. This is a common objective of the International Association and the New Zealand Society for Earthquake Engineering, and other similar organizations.

We are, indeed, grateful for this new effort by the New Zeal and Society, and offer our full cooperation toward the attainment of our mutual goals. In doing this, a crystal-clear understanding of what those goals are is, of course, most helpful. I am sure that the goals should include a balance between what I have here called the science and the art of earthquake engineering. I am equally sure that the New Zealand Society for

- Earthquake Engineering has the same broad goal in mind. To this end, we can only say Godspeed.

John E. Rinne

President, IAEE

April 13, 1968 